\title{
Short communication: Diagnosis and classification of clinical and subclinical mastitis utilizing a dynamometer and a handheld infrared thermometer
}

\author{
L. Wollowski, S. Bertulat, A. Kossatz, and W. Heuwieser* \\ Clinic for Animal Reproduction, Faculty of Veterinary Medicine, Freie Universität Berlin, Koenigsweg 65, 14163 Berlin, Germany
}

\begin{abstract}
In times of ongoing automatization of dairy cow husbandry, objective and reliable tools for mastitis diagnostic are highly in demand. The objective of this study was to investigate the diagnostic value of a handheld dynamometer and an infrared thermometer to diagnose and score clinical and subclinical mastitis and to compare those values with results from palpation of the udder tissue. Overall, 218 cows with clinical mastitis (i.e., 46 mild, 106 moderate, and 66 severe cases), 142 with subclinical mastitis, and 68 healthy cows were enrolled. Our data provide evidence that the dynamometer is an accurate diagnostic tool to differentiate between healthy udder quarters, and those with subclinical and clinical mastitis. Furthermore, the severity score of clinical mastitis can be estimated by dynamometer. The firmness threshold for the detection of clinical mastitis was $1.002 \mathrm{~kg}$. Using a threshold of $1.175 \mathrm{~kg}$ in clinical mastitis quarters, it was possible to differentiate between negative and positive bacteriological results. A differentiation between healthy and clinical mastitis quarters with the infrared thermometer was possible, albeit udder surface temperatures were highly influenced by ambient temperature. Udder surface temperature increased by 0.15 to $0.18^{\circ} \mathrm{C}$ for each degree of ambient temperature. In conclusion, the utility of an infrared thermometer to estimate the udder health status of dairy cows is limited, whereas the handheld dynamometer appeared to be an accurate and objective method.
\end{abstract}

Key words: udder firmness, udder surface temperature, dynamometer, mastitis diagnosis

\section{Short Communication}

Today's dairy industry with its increasing herd sizes (Barkema et al., 2015) and ongoing automatization of the milking process requires objective parameters for

Received August 7, 2018.

Accepted March 19, 2019

*Corresponding author: w.heuwieser@fu-berlin.de the detection of mastitis to reduce its economic effect (Ruegg, 2017). Effective diagnostic methods can lead to faster and more efficient control of mastitis and promote responsible use of antimicrobials (Kroemker and Leimbach, 2017). It is also important to reliably score the severity of clinical mastitis $(\mathbf{C M})$ to predict treatment outcomes (Royster and Wagner, 2015) and adapt treatment protocols accordingly (Roberson, 2003). Although most dairy farmers and veterinarians focus on detection, treatment, and prevention of $\mathrm{CM}$, management of subclinical mastitis (SCM) is also important (Halasa et al., 2007) because it influences milk yield and overall productivity (Ruegg, 2017). Diagnostic methods for SCM are usually based on SCC. Unfortunately, those methods entail the collection of milk (e.g., California mastitis test, electrical conductivity) and thus limit their applicability (Ruegg, 2017), or lack accuracy (e.g., $N$-acetyl- $\beta$-D-glucosaminidase, lactate dehydrogenase, Nyman et al., 2016). Overall, there is a lack of easy to use, objective cow-side methods to diagnose SCM and $\mathrm{CM}$ that furthermore provide thresholds that can be used as relevant control points in standard operation procedures (SOP).

Although some evidence indicates that the measurement of udder firmness utilizing a dynamometer can be used to diagnose CM (Rees et al., 2017), studies differentiating different severity scores or pathogens are missing. The diagnostic value of this method to differentiate between healthy quarters and quarters with SCM and CM has yet to be investigated.

Because udder surface temperature (UST) seems to rise in mastitis quarters just as SCC increases (Sathiyabarathi et al., 2016b), several researchers have investigated the accuracy of diagnosing CM (Metzner et al., 2014; Sathiyabarathi et al., 2016a) and SCM (Berry et al., 2003; Polat et al., 2010) using infrared thermography (IRT). While this technique measures the whole udder, we wanted to evaluate whether a smaller, less expensive device, such as a handheld infrared thermometer, which measures only a part of the udder, is also able to diagnose mastitis. Such devices were validated for measurements of ear surface temperature in cows with hypocalcemia (Venjakob et al., 2016). An applica- 
tion in cows with mastitis might be feasible but has not yet been investigated.

Therefore, the overall objective of this study was to investigate the diagnostic value of 2 handheld devices (i.e., an infrared thermometer and a dynamometer for udder health monitoring). Specifically, we set out (1) to determine the accuracy of each devices to differentiate between CM, SCM, and healthy udder quarters, (2) to determine the accuracy of each device to differentiate between mild, moderate, and severe CM, (3) to determine the accuracy of each device to differentiate between gram-positive and gram-negative pathogens and no growth in CM cases, and (4) to compare surface temperature and udder firmness measured with those 2 devices with results acquired by palpation of the udder tissue.

The study was conducted between June 2016 and January 2017 on a commercial dairy farm in Brandenburg, Germany, housing approximately 2,500 dairy cows (305-d milk yield 9,839 $\pm 1,887 \mathrm{~kg}$; mean $\pm \mathrm{SD}$ ). Overall, 251 Holstein Friesian dairy cows with CM, 150 with SCM, and 70 healthy cows were enrolled. Cows were between 1st and 9th lactation $(2.9 \pm 1.5)$, and on average $168.7 \pm 113.7$ DIM. They were housed in a freestall barn with slatted flooring and stall cubicles equipped with rubber mats and had ad libitum access to water. Cows were fed a balanced TMR twice daily and were managed according to the guidelines set by the International Cooperation on Harmonization of Technical Requirements for Registration of Veterinary Medicinal Products (Hellmann and Radeloff, 2000). Fresh cows and high lactating cows were milked 3 times a day and late lactating cows 2 times a day in a 56 -stall headin rotary milking parlor, respectively. Special groups (i.e., hospital pen, colostrum, and mastitis group) were milked twice daily in a $2 \times 10$ herringbone milking parlor.

Cows with signs of CM (i.e., clotted milk, heat, or swelling of the udder) that were identified by milking personnel during regular milking were separated and examined by 1 out of 5 investigators. Before initiation of the study, the investigators were trained in the following manner. Based on information gathered from the scientific literature (i.e., palpation of firmness: Gleeson et al., 2007; measuring firmness with a dynamometer: Bertulat et al., 2012; palpation of UST: Hoeksma and Faber, 2000; measuring UST with a handheld infrared thermometer: Sathiyabarathi et al., 2016b; Venjakob et al., 2016), a first version of an SOP was written that all investigators read and had to follow. Furthermore, several training sessions were carried out before the study started. When disagreement occurred between investigators during those sessions, the findings were discussed, definitions were reviewed, and the examina- tions were repeated until agreement was reached. The SOP was then finalized and implemented.

Healthy cows and those with SCM were preselected based on most recent DHIA results (i.e., SCC $<10,000$ cells $/ \mathrm{mL}$ and $\mathrm{SCC}>1,000,000$ cells $/ \mathrm{mL}$ ). Cows with $\mathrm{CM}$ within the last $30 \mathrm{~d}$ before enrollment, with signs of metabolic or infectious disease (e.g., ketosis or metritis) and cows that received any treatments (e.g., antimicrobials or anti-inflammatory drugs) were excluded from the study. Moreover, cows with teat lesions or lacerations of the udder surface, with CM in 2 or more quarters, and within $5 \mathrm{~d}$ after calving were not enrolled. Healthy quarters with a positive bacteriological result were retrospectively withdrawn.

After general examination (i.e., rectal temperature, pulse, and respiration rate) of each cow, an examination of the udder was conducted including milk sampling and California mastitis test (KerbaTEST, Albert Kerbl GmbH, Buchbach, Germany). Only one quarter per cow was included in the study. In case of CM, the mastitis quarter was chosen. In cows with SCM and in healthy cows, the quarter was chosen based in California mastitis test results (e.g., healthy: 0, SCM: ++ or +++ ). If 2 or more quarters of a cow fulfilled the requirements for enrollment, the study quarter was selected based on convenience (e.g., best milkability, cleanliness). Sterile milk samples of each selected quarter were collected for bacteriological culturing and sent to accredited laboratories. Examinations of udder firmness and UST followed a previously established SOP to minimize the effect of investigator and ensure that all cows were examined and classified in the same manner. Udder firmness was scored by palpation based on a scoring system validated by Gleeson et al. (2007). In brief, score 0 equals a soft udder, yielding significantly to gentle pressure from the finger and score 3 is used for very firm udders, not yielding to pressure. Udder skin temperature was scored on a 4-point scale similar to a scoring system that Hoeksma and Faber (2000) used to assessed skin temperature in leprosy patients (i.e., 0 $=$ UST comparable to temperature of the flanks, $1=$ mild, $2=$ moderate, and $3=$ strong increase compared with surface temperature of the flanks). Investigators determined firmness and UST independent from each other. Udder firmness was also measured with a dynamometer (Penefel DFT14, Agro Technologie, Forgesles-Eaux, France) according to the SOP described by Bertulat et al. (2012) and applied by Rees et al. (2017). Udder surface temperature was measured with a handheld infrared thermometer (Fluke 568 IR Thermometer, Fluke Deutschland GmbH, Glottertal, Germany) at a distance of $1 \mathrm{~m}$, resulting in a measured area of 2 $\mathrm{cm}$ in diameter on the udder surface (Sathiyabarathi et al., 2016b; Venjakob et al., 2016). The measuring 
point for both devices was located in the horizontal and vertical middle of the quarter. Forequarters were measured from the lateral side and hindquarters from the posterior side of the udder (Bertulat et al., 2012; Sathiyabarathi et al., 2016b).

All cases of CM were classified into mild (abnormal appearance of milk), moderate (abnormal appearance of milk accompanied by swelling or redness of the mammary gland), and severe CM (in addition to signs of local inflammation systemic illness such as fever above $39.5^{\circ} \mathrm{C}$ ) according to Wenz et al. (2001) with slight modifications implemented by Pinzon-Sanchez and Ruegg (2011).

After examinations, cows were treated according to the SOP implemented on the farm. Climate loggers (Tinytag Plus II, Germini Loggers Ltd., Chichester, UK) were placed securely in the middle alley of the different pens collecting data on ambient temperature every hour.

Data were entered into Excel spreadsheets (version 2016, Microsoft Corp., Redmond, WA) and statistical analyses were performed with SPSS for Windows (SPSS, version 24.0, IBM Deutschland GmbH, Ehningen, Germany). The statistical significance level was set at $P \leq 0.05$ and trends were discussed at $P<0.10$. The bacteriological results were categorized based on Gram staining characteristics (i.e., gram-negative, grampositive, and no growth). Normality of distributions of continuous parameters (i.e., udder firmness, UST) was assessed by plotting the data, visual examination, and calculating a quantile-quantile plot. To calculate the effect of udder health status (i.e., CM, SCM, or healthy) on udder firmness measured by dynamometer or UST measured by infrared thermometer, linear models were used. All models were built according to the model building strategies published by Dohoo et al. (2009) and described by Bertulat et al. (2017). In brief, all independent parameters were initially tested with Spearman's correlation or Pearson correlation for collinearity and analyzed in a univariate univariable model. Only parameters resulting in univariable models with $P \leq$ 0.2 were included in the final multivariable univariate model. If 2 parameters showed a high, significant correlation $(\mathrm{r}<-0.6 ; \mathrm{r}>0.6)$, only the parameter with the smallest $P$-value was used in the final model. The final model was built in a conditional backward stepwise manner. Interactions were tested for all relevant parameters (e.g., DIM with milk yield, lactation number with total number of episodes with recurrent CM, and Gram staining characteristics and severity score of $\mathrm{CM})$. Post hoc comparison was carried out applying the least significant difference test. Validity of the final models was ensured by checking that the model assumptions were met, especially the normality of distri- bution of residues was verified using the Shapiro-Wilk and Kolmogorov-Smirnov test, plotting the residues, and calculating a quantile-quantile plot. Concerning the effect of udder quarter health status, 2 separate models were calculated using either udder firmness or UST as outcome variable. Model building was repeated with severity score of CM (i.e., mild, moderate, severe) instead of udder health status. The following parameters were furthermore tested: lactation number, DIM, milk yield, total number of episodes with recurrent CM, time after milking, ambient temperature, investigator, quarter position, and Gram staining characteristics. For ordinal variables (e.g., palpation of udder firmness and UST), a generalized linear model for ordinal variables was used. Model building was done in the same way as described before. A multinomial logistic regression was used to determine if any confounders could have had an influence on the udder health status or Gram staining characteristics and thus would require a modification of the calculations of sensitivity (Se) and specificity (Sp) as described by Coughlin et al. (1992). The effects of lactation number, DIM, milk yield, total number of episodes with recurrent CM, time after milking, ambient temperature, investigator, and quarter position on the odds for udder quarters to develop a SCM or CM and for udder quarters having different bacteriological results were assessed. Receiver operating characteristic curves were calculated to establish thresholds between cows with and without mastitis or with negative and positive bacteriological results. Interpretation of receiver operating characteristic curves was based on the area under the curve (AUC). The best thresholds were chosen based on the highest sum of Se and Sp. To evaluate the relationship between manually determined and measured values of UST and firmness, Spearman's correlation coefficients were calculated.

Overall, 218 cows with CM (i.e., 46 mild, 106 moderate, 66 severe), 142 with SCM, and 68 healthy cows met all inclusion criteria. Thirty-four, 7 , and 2 cows had to be excluded because of a CM within $30 \mathrm{~d}$ before enrollment, a positive bacteriological result, and signs of metabolic or infectious disease (e.g., metritis claw lesions or ketosis), respectively.

Milk samples categorized as gram-positive included Streptococcus uberis (35\%), Streptococcus agalactiae (17\%), Staphylococcus aureus (17\%), CNS (13\%), Streptococcus dysgalactiae (7\%), and other Streptococcus spp. (11\%). In gram-negative samples, coliform bacteria (56\%), Escherichia coli (41\%), and Klebsiella spp. $(3 \%)$ were found. The distribution of different bacteria strains within different severity scores of CM is shown in Table 1.

The distribution of udder firmness values in quarters with different health status are shown in Figure 1. 
Udder firmness measured by dynamometer in healthy quarters, quarters with SCM, and quarters with CM averaged $1.054 \pm 0.13,1.394 \pm 0.09$, and $1.974 \pm 0.06$ $\mathrm{kg}(\mathrm{LSM} \pm \mathrm{SE})$, respectively. Quarters of different udder health status differed in their udder firmness between each other $(P<0.001)$. No effect was observed of lactation number, DIM, milk yield, total number of episodes with recurrent $\mathrm{CM}$, time after milking, ambient temperature, investigator, and quarter position on udder firmness $(P>0.05)$. Considering severity scores within CM quarters, udder firmness averaged $1.478 \pm$ $0.17,1.726 \pm 0.11$, and $2.550 \pm 0.13 \mathrm{~kg}$ in mild, moderate, and severe cases, respectively. Within cows with $\mathrm{CM}$, severity score and Gram staining characteristics had a significant overall effect on udder firmness measured by a dynamometer $(P<0.001)$. Measurement results of quarters of different severity scores of $\mathrm{CM}$ differed significantly between each other $(P<0.001)$. Gram-negative tested quarters $(2.234 \pm 0.17 \mathrm{~kg})$ tended to be firmer compared with quarters infected with gram-positive strains $(1.882 \pm 0.11 \mathrm{~kg} ; P=0.080)$. A bacteriological negative result was associated with lower firmness $(1.638 \pm 0.13 \mathrm{~kg} ; P=0.007)$ compared with gram-negative, but not to gram-positive mastitis pathogens $(P=0.147)$.

Based on the multinomial logistic regression, no effect of any of the tested confounders on the odds for an udder quarter being classified as SCM or CM instead of being healthy was found. These tested factors also did not influence the odds for having gram-positive, gram-negative, or culture-negative results.

The threshold providing the highest accuracy (Se $=0.73, \mathrm{Sp}=0.88)$ for differentiating between healthy and mastitis quarters was $1.002 \mathrm{~kg}(\mathrm{AUC}=0.832$, $P<0.001)$. In CM quarters, a threshold of $1.175 \mathrm{~kg}$ $(\mathrm{Se}=0.70, \mathrm{Sp}=0.62, \mathrm{AUC}=0.704, P<0.001)$ was established to differentiate between bacteriologically negative and positive. These thresholds do not meet the recommendations (e.g., $\mathrm{Se}=0.80, \mathrm{Sp}>0.99$ ) of the International Organization for Standardization (ISO/FDIS 20966) for diagnostic tests in automatic milking systems (ISO, 2007). Nevertheless, compared with electrical conductivity measurements (i.e., SCM: $\mathrm{Se}=0.194, \mathrm{Sp}=0.919 ; \mathrm{CM}: \mathrm{Se}=0.479, \mathrm{Sp}=0.919$; Norberg et al., 2004), udder firmness is more accurate.

Our results support the assumptions of previous studies that udder firmness is a reliable indicator to identify CM (Swinkels et al., 2013; Fogsgaard et al., 2015). To evaluate a successful application of a dynamometer to diagnose and classify SCM and CM in the field, further studies are warranted because the inclusion criteria for cows in our trial and the thorough diagnostics of all mastitis cases allowed us to generate a data set that might differ from mastitis cases detected in day to day routine on commercial dairy farms. Nevertheless, our results confirm findings from Rees et al. (2017) that cows with CM had firmer udders compared with healthy cows. In contrast to the aforementioned study, we additionally were able to show that Gram staining characteristics (i.e., gram-positive, gram-negative, or no growth) affected udder firmness in mastitis quarters. No growth and gram-negative quarters differed significantly, and only a tendency was detected for different udder firmness values in gram-positive and gram-negative quarters. Interestingly, in our study udder firmness in cows with CM was approximately $80 \%$ higher compared with values reported by Rees et al. (2017), whereas values in healthy quarters were similar. In our study front and hind quarters were measured, but only hind quarters were included previously (Rees et al., 2017). These different types of quarters in both studies might be an explanation for differences in udder

Table 1. Cross table of bacteriological results of quarter milk samples against clinical mastitis of different severity score (e.g., mild, moderate, and severe)

\begin{tabular}{lrrrr}
\hline & \multicolumn{3}{c}{ Clinical mastitis } \\
\cline { 2 - 3 } Item & Mild & Moderate & Severe & Sum \\
\hline Bacteria strain & & & & \\
Staphylococcus aureus & 4 & 6 & 4 & 14 \\
CNS & 0 & 1 & 0 & 1 \\
Streptococcus uberis & 3 & 13 & 11 & 27 \\
Streptococcus agalactiae & 3 & 6 & 7 & 18 \\
Streptococcus dysgalactiae & 2 & 5 & 0 & 8 \\
Other Streptococcus & 3 & 5 & 15 & 18 \\
Coliform bacteria & 2 & 6 & 9 & 17 \\
Escherichia coli & 0 & 0 & 1 & 1 \\
Klebsiella spp. & 0 & 0 & 1 & 1 \\
Trueperella pyogenes & 23 & 41 & 62 & 72 \\
Culture-negative & 45 & 93 & & 200 \\
Sum & & & 62 \\
\hline
\end{tabular}




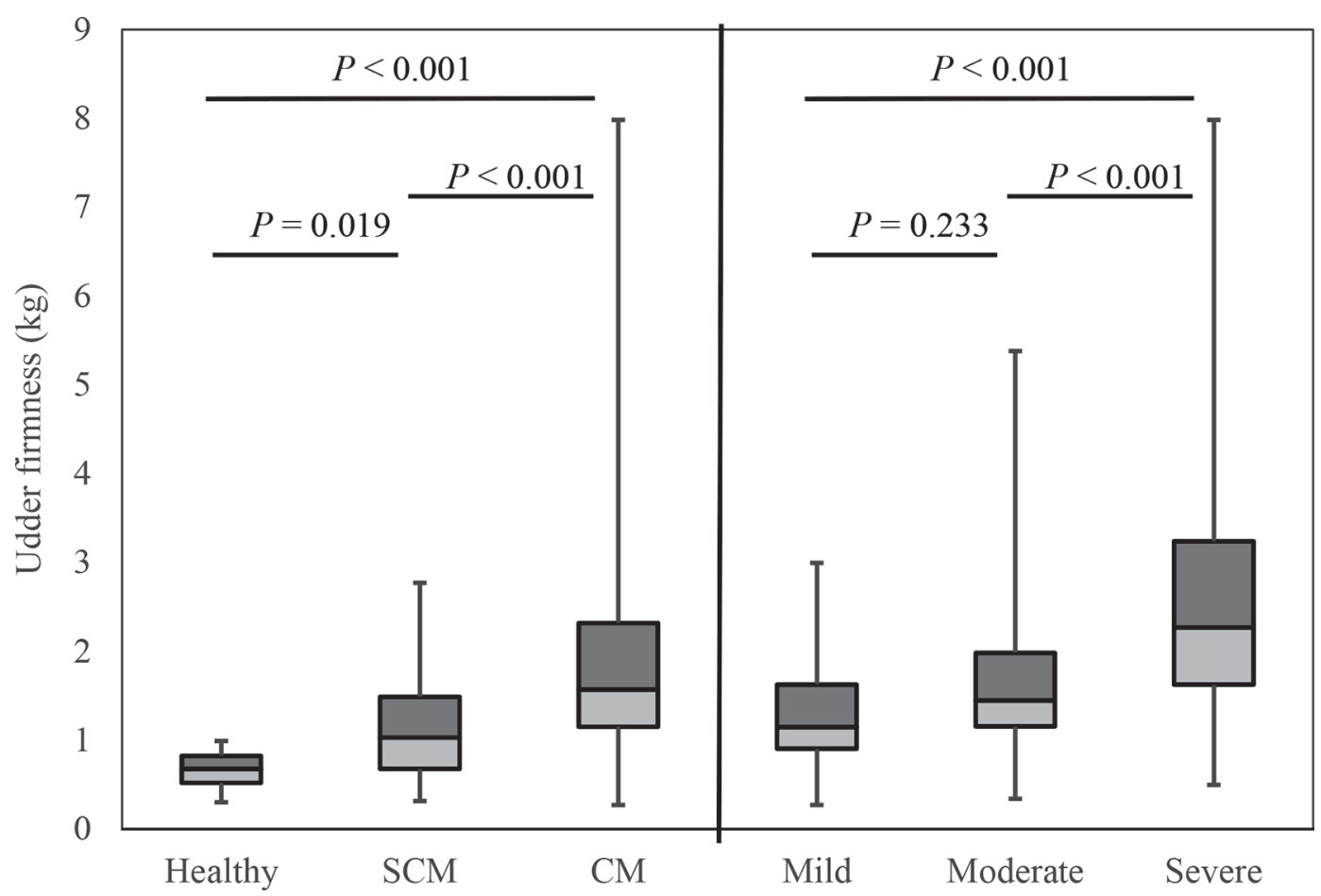

Figure 1. Boxplots depicting udder firmness $(\mathrm{kg})$ in udder quarters with different health status (left side: healthy $=68$ healthy quarters, $\mathrm{SCM}=142$ quarters with subclinical mastitis, $\mathrm{CM}=218$ quarters with clinical mastitis; right side: CM quarters with different severity scores, 46 cows with mild, 106 with moderate, and 66 with severe CM). The black line inside each box marks the mean; the bottom and top of the boxes are the first and third quartiles; and whiskers end at the smallest and largest statistical values.

firmness, although in healthy cows, front quarters are less firm than hind quarters (Bertulat et al., 2012). So far no data are available from CM cows, but it might be hypothesized that CM leads to higher firmness values in front quarters.

Considering palpation, an overall effect of different health status (i.e., CM, SCM, healthy; $P<0.001$ ), Gram staining characteristics $(P<0.001)$, and time after milking $(P=0.022)$ on udder firmness could be evaluated with no effect of further tested factors $(P$ $>0.05)$. Most healthy quarters were scored 0 during palpation. Higher scores were found more frequently in CM and SCM quarters (Figure 2). Healthy quarters differed significantly from quarters with SCM $(P=$ $0.003)$ and $\mathrm{CM}(P<0.001)$. Additionally, SCM differed from $\mathrm{CM}$ quarters $(P<0.001)$. In $\mathrm{CM}$ cows, severity score $(P<0.001)$ and Gram staining characteristic $(P$ $=0.018)$ had an effect on the palpation score. With increasing severity score of CM, higher scores of udder firmness were given by palpation (Figure 2).

In agreement with previous studies (Rees et al., 2014), a strong correlation between palpation of udder firmness and measurements by dynamometer was found ( $\mathrm{r}$ $=0.749, P<0.001)$. Considering our results, the differentiation between healthy quarters and those with $\mathrm{CM}$ and SCM and between different severity scores of CM by palpation is possible. Nevertheless, palpation is still a subjective parameter with limited repeatability when multiple observers are involved (Houe et al., 2002; Rees et al., 2014). Also, in our study, the knowledge that a given cow was healthy or had a CM before palpation could have had an influence on the estimation.

The UST measured by a handheld infrared thermometer ranged from 25.0 to $39.8^{\circ} \mathrm{C}$. It was affected by the health status of a quarter and ambient temperature $(P$ $<0.001$, Table 2$)$ but not by the other tested factors $(P$ $>0.05)$. Udder quarters with $\mathrm{CM}\left(35.1 \pm 0.1^{\circ} \mathrm{C}\right)$ had higher UST than those with SCM $\left(33.7 \pm 0.2^{\circ} \mathrm{C} ; P<\right.$ $0.001)$ and healthy quarters $\left(34.4 \pm 0.2^{\circ} \mathrm{C} ; P<0.001\right)$. Healthy quarters differed from CM and SCM quarters $(P<0.001)$. Within CM quarters, the UST depended on ambient temperature $(P<0.001)$ and severity score $(P=0.037)$, but not on the other tested factors $(P>$ $0.05)$. Udder quarters with mild $\mathrm{CM}\left(35.1 \pm 0.4^{\circ} \mathrm{C}\right)$ tended to be cooler than those with moderate $(35.4 \pm$ $\left.0.4^{\circ} \mathrm{C}, P=0.088\right)$ and severe $\mathrm{CM}\left(35.6 \pm 0.4^{\circ} \mathrm{C}, P=\right.$ $0.010)$. Moderate and severe CM quarters did not differ $(P=0.223)$. The correlation between palpation of UST and measurements by infrared thermometer was fair $(\mathrm{r}$ $=0.454, P<0.001)$.

The UST estimated by palpation (Figure 2) was scored 0 in all healthy quarters. Subclinical quarters 

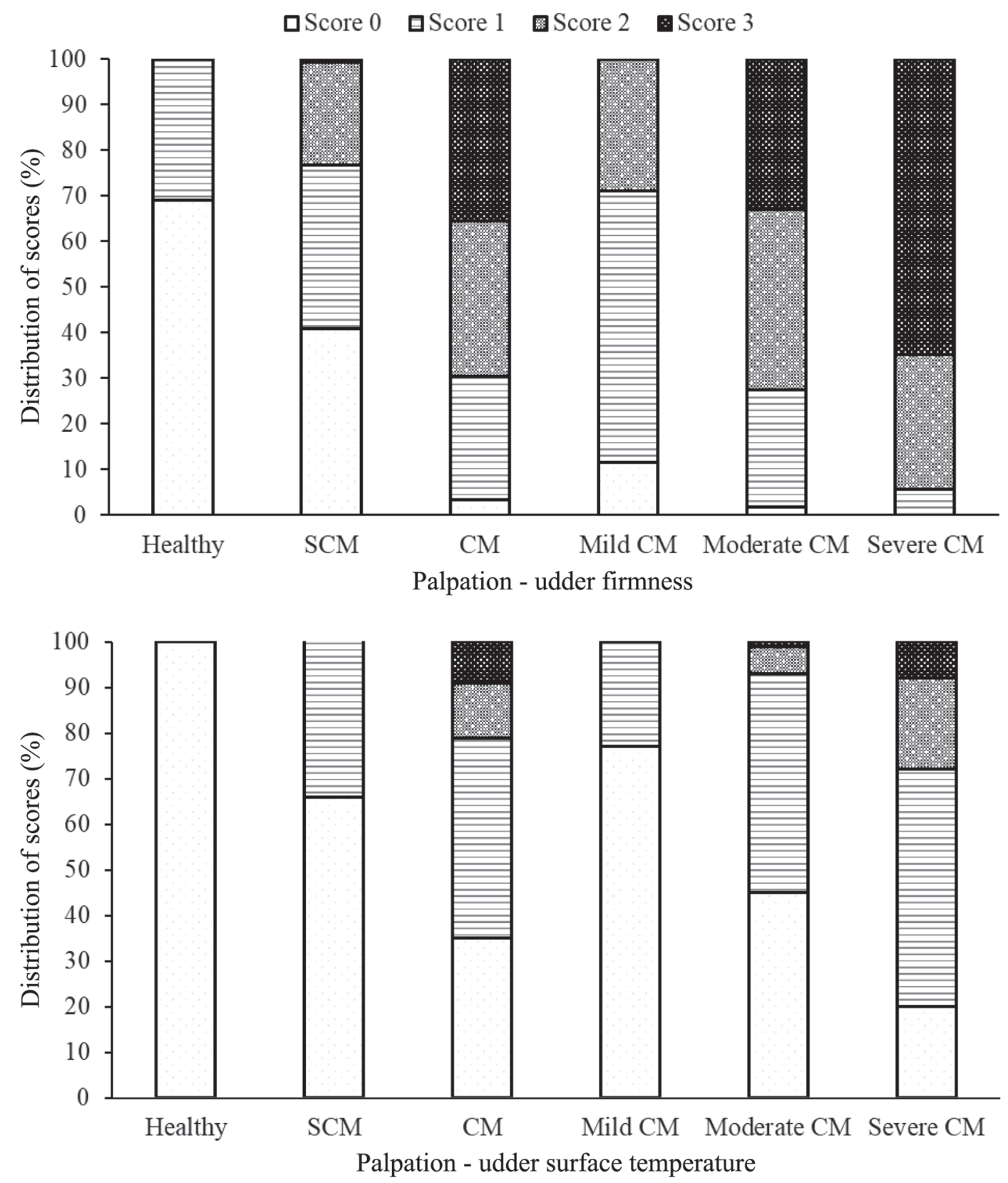

Figure 2. Distribution of palpation scores of udder firmness (top; i.e., 0 to 3; soft to very firm) and udder surface temperature (bottom; i.e., 0 to 3 ; no increase to strong increase compared with body surface temperature of the flanks) in 68 healthy quarters, 142 quarters with subclinical mastitis (SCM), and 218 with clinical mastitis (CM) of different severity scores (i.e., mild: 46, moderate: 106, and severe: 66).

were equally often diagnosed as 0 and 1 . In CM cases, scores ranged between 0 and 3. Scores of SCM quarters differed from healthy $(P=0.003)$ and $\mathrm{CM}(P<$ 0.001) quarters. Within CM quarters, palpation results of UST differed between severity scores $(P<0.001)$. With increasing severity score, higher scores of UST were given by palpation (Figure 2).

In contrast to previous publications (Colak et al., 2008; Zaninelli et al., 2018), UST measured by IRT was lowest in SCM quarters. Our results of UST scores determined by palpation, however, had the lowest scores in healthy quarters. During palpation all quarters were briefly palpated and sampled, making sure that only one quarter was affected. An unconscious comparison of quarters within a cow is likely and might have had an influence on scoring. Elevated UST observed in CM quarters may be explained by an increased blood flow (Dhondt et al., 1977). Bortolami et al. (2015) supports 
Table 2. Two separate generalized linear mixed models showing the influence of ambient temperature $(P<$ $0.001)$ on udder surface temperature in cows with different udder health status $(P<0.001$, model A) and in cows with different severity scores of clinical mastitis $(P=0.037$, model $\mathrm{B})$ measured with a handheld infrared thermometer $^{1}$

\begin{tabular}{llccc}
\hline Model & Variable & Estimate & SE & $P$-value \\
\hline A & Intercept & 30.43 & 1.49 & $<0.001$ \\
& Ambient temperature & 0.18 & 0.16 & $<0.001$ \\
Udder health status & & Referent & \\
Healthy & & 0.19 & $<0.001$ \\
& Subclinical mastitis & -0.89 & 0.15 & 0.001 \\
& Clinical mastitis & 0.51 & 0.61 & $<0.001$ \\
& Intercept & 31.52 & 0.02 & $<0.001$ \\
Ambient temperature & 0.15 & & \\
Clinical mastitis & & Referent & \\
Mild & & 0.19 & 0.088 \\
& Moderate & 0.33 & 0.20 & 0.010
\end{tabular}

${ }^{1}$ Data are based on 68 healthy quarters, 142 quarters with subclinical mastitis, and 218 quarters with clinical mastitis (46 cows with mild, 106 with moderate, and 66 with severe clinical mastitis).

our findings and assumes that a deviation of blood flow during SCM could cause a decrease in UST.

Overall, it has to be considered that the strong effect of ambient temperature on UST compromised the diagnostic value of IRT in mastitis (Berry et al., 2003; Castro-Costa et al., 2014). Similar confounders have been described for other applications such as the measurement of ear temperature in cows with hypocalcemia (Venjakob et al., 2016) or claw temperature (Gloster et al., 2011) in lame cows. In our study UST increased by 0.15 to $0.18^{\circ} \mathrm{C}$ for each degree of ambient temperature (Table 2). In comparison, the effect of mastitis was negligible (i.e., $0.51^{\circ} \mathrm{C}$ in $\mathrm{CM} ;-0.89$ in $\mathrm{SCM}$ compared with healthy quarters). Considering these results, an application in the field seems to be limited and a calculation of thresholds was not reasonable.

In conclusion, it could be demonstrated that the measurement of udder firmness by using a handheld dynamometer is an accurate and objective method to estimate the udder health status of dairy cows (e.g., $\mathrm{CM}$, SCM, and healthy udder quarters). Within CM, severity scores and Gram staining characteristics affected udder firmness. Severe CM quarters differed from mild and moderate CM $(P<0.001)$ and quarters with a bacteriological negative result differed significantly from gram-negative tested quarters $(P=0.007)$. Therefore, in times of continuing automatization, the dynamometer might be a valuable alternative to reliably diagnose mastitis. Udder firmness thresholds can help to preselect cows for further examination and might be used as critical control points in SOP for diagnostic classifications and treatment decisions. Further studies, however, are warranted to confirm that our results can be transferred to other farms with different mastitis pathogens and different climatic conditions and that calculated thresholds are valid on those farms as well.
The diagnostic value of measuring UST with a handheld thermometer to detect SCM and CM and differentiate between severity scores is very limited because ambient temperature has a strong effect on UST. Nevertheless, a differentiation between quarters of different health status was possible. Differentiation between severity scores in CM, however, was not possible. The discrepancy between palpation results of UST and results gained by IRT should be further investigated.

\section{ACKNOWLEDGMENTS}

We thank the staff of the Clinic of Animal Reproduction, Freie Universität Berlin (Berlin, Germany) and the participating dairy farm for their cooperation. Special thanks to the farm staff for their fantastic support. L. Wollowski was partly funded by Tiergyn Berlin e.V. (Berlin, Germany).

\section{REFERENCES}

Barkema, H. W., M. A. von Keyserlingk, J. P. Kastelic, T. J. Lam, C. Luby, J. P. Roy, S. J. LeBlanc, G. P. Keefe, and D. F. Kelton. 2015. Invited review: Changes in the dairy industry affecting dairy cattle health and welfare. J. Dairy Sci. 98:7426-7445.

Berry, R. J., D. Kennedy, L. Scott, L. Kyle, and L. Schaefer. 2003 Daily variation in the udder surface temperature of dairy cows measured by infrared thermography: Potential for mastitis detection. Can. J. Anim. Sci. 83:687-693.

Bertulat, S., C. Fischer-Tenhagen, A. Werner, and W. Heuwieser. 2012. Technical note: Validating a dynamometer for noninvasive measuring of udder firmness in dairy cows. J. Dairy Sci. 95:6550-6556.

Bertulat, S., N. Isaka, A. de Prado, A. Lopez, T. Hetreau, and W. Heuwieser. 2017. Effect of a single injection of cabergoline at dry off on udder characteristics in high-yielding dairy cows. J. Dairy Sci. 100:3220-3232.

Bortolami, A., E. Fiore, M. Gianesella, M. Corro, S. Catania, and M. Morgante. 2015. Evaluation of the udder health status in subclinical mastitis affected dairy cows through bacteriological culture, somatic cell count and thermographic imaging. Pol. J. Vet. Sci. 18:799-805. 
Castro-Costa, A., G. Caja, A. A. Salama, M. Rovai, C. Flores, and J. Aguilo. 2014. Thermographic variation of the udder of dairy ewes in early lactation and following an Escherichia coli endotoxin intramammary challenge in late lactation. J. Dairy Sci. 97:1377-1387.

Colak, A., B. Polat, Z. Okumus, M. Kaya, L. E. Yanmaz, and A. Hayirli. 2008. Short communication: Early detection of mastitis using infrared thermography in dairy cows. J. Dairy Sci. 91:4244-4248.

Coughlin, S. S., B. Trock, M. H. Criqui, L. W. Pickle, D. Browner, and M. C. Tefft. 1992. The logistic modeling of sensitivity, specificity, and predictive value of a diagnostic test. J. Clin. Epidemiol. $45: 1-7$.

Dhondt, G., C. Burvenich, and G. Peeters. 1977. Mammary blood flow during experimental Escherichia coli endotoxin induced mastitis in goats and cows. J. Dairy Res. 44:433-440.

Dohoo, I. R., S. W. Martin, and H. Stryhn. 2009. Veterinary Epidemiologic Research. 2nd ed. University of Prince Edward Island, Charlottetown, PEI, Canada.

Fogsgaard, K. K., T. W. Bennedsgaard, and M. S. Herskin. 2015. Behavioral changes in freestall-housed dairy cows with naturally occurring clinical mastitis. J. Dairy Sci. 98:1730-1738.

Gleeson, D. E., B. O'Brien, L. Boyle, and B. Earley. 2007. Effect of milking frequency and nutritional level on aspects of the health and welfare of dairy cows. Animal 1:125-132.

Gloster, J., K. Ebert, S. Gubbins, J. Bashiruddin, and D. J. Paton. 2011. Normal variation in thermal radiated temperature in cattle: Implications for foot-and-mouth disease detection. BMC Vet. Res. 7:73.

Halasa, T., K. Huijps, O. Osteras, and H. Hogeveen. 2007. Economic effects of bovine mastitis and mastitis management: A review. Vet. Q. 29:18-31.

Hellmann, K., and I. Radeloff. 2000. Guidance for industry: Good clinical practice. International Cooperation on Harmonisation of Technical Requirements for Registration of Veterinary Medicinal Products (VICH). VICH, Brussels, Belgium. http://www.fda.gov/ downloads/AnimalVeterinary/GuidanceComplianceEnforcement/ GuidanceforIndustry/UCM052417.pdf.

Hoeksma, A. F., and W. R. Faber. 2000. Assessment of skin temperature by palpation in leprosy patients: Interobserver reliability and correlation with infrared thermometry. Int. J. Lepr. Other Mycobact. Dis. 68:65-67.

Houe, H., M. Vaarst, and C. Enevoldsen. 2002. Clinical parameters for assessment of udder health in Danish dairy herds. Acta Vet. Scand. 43:173-184.

ISO (International Organization for Standardization). 2007. Automatic milking systems-Requirements and testing. ISO 20966. Annex C: Example of methods of evaluating detection systems for milk deemed as abnormal due to blood or changes in homogeneity. ISO, Geneva, Switzerland.

Kroemker, V., and S. Leimbach. 2017. Mastitis treatment-Reduction in antibiotic usage in dairy cows. Reprod. Domest. Anim. 52(Suppl 3):21-29.

Metzner, M., C. Sauter-Louis, A. Seemueller, W. Petzl, and W. Klee. 2014. Infrared thermography of the udder surface of dairy cattle: Characteristics, methods, and correlation with rectal temperature. Vet. J. 199:57-62.
Norberg, E., H. Hogeveen, I. R. Korsgaard, N. C. Friggens, K. H. Sloth, and P. Lovendahl. 2004. Electrical conductivity of milk: Ability to predict mastitis status. J. Dairy Sci. 87:1099-1107.

Nyman, A. K., U. Emanuelson, and K. P. Waller. 2016. Diagnostic test performance of somatic cell count, lactate dehydrogenase, and $\mathrm{N}$-acetyl-beta-D-glucosaminidase for detecting dairy cows with intramammary infection. J. Dairy Sci. 99:1440-1448.

Pinzon-Sanchez, C., and P. L. Ruegg. 2011. Risk factors associated with short-term post-treatment outcomes of clinical mastitis. J. Dairy Sci. 94:3397-3410.

Polat, B., A. Colak, M. Cengiz, L. E. Yanmaz, H. Oral, A. Bastan, S. Kaya, and A. Hayirli. 2010. Sensitivity and specificity of infrared thermography in detection of subclinical mastitis in dairy cows. J. Dairy Sci. 93:3525-3532.

Rees, A., C. Fischer-Tenhagen, and W. Heuwieser. 2014. Evaluation of udder firmness by palpation and a dynamometer. J. Dairy Sci. 97:3488-3497.

Rees, A., C. Fischer-Tenhagen, and W. Heuwieser. 2017. Udder firmness as a possible indicator for clinical mastitis. J. Dairy Sci. 100:2170-2183.

Roberson, J. R. 2003. Establishing treatment protocols for clinical mastitis. Vet. Clin. North Am. Food Anim. Pract. 19:223-234.

Royster, E., and S. Wagner. 2015. Treatment of mastitis in cattle. Vet. Clin. North Am. Food Anim. Pract. 31:17-46.

Ruegg, P. L. 2017. A 100-year review: Mastitis detection, management, and prevention. J. Dairy Sci. 100:10381-10397.

Sathiyabarathi, M., S. Jeyakumar, A. Manimaran, G. Jayaprakash, H. A. Pushpadass, M. Sivaram, K. P. Ramesha, D. N. Das, M. A. Kataktalware, M. A. Prakash, and R. D. Kumar. 2016a. Infrared thermography: A potential noninvasive tool to monitor udder health status in dairy cows. Vet. World 9:1075-1081.

Sathiyabarathi, M., S. Jeyakumar, A. Manimaran, H. A. Pushpadass, M. Sivaram, K. P. Ramesha, D. N. Das, M. A. Kataktalware, G. Jayaprakash, and T. K. Patbandha. 2016b. Investigation of body and udder skin surface temperature differentials as an early indicator of mastitis in Holstein Friesian crossbred cows using digital infrared thermography technique. Vet. World 9:1386-1391.

Swinkels, J. M., P. Cox, Y. H. Schukken, and T. J. Lam. 2013. Efficacy of extended cefquinome treatment of clinical Staphylococcus aureus mastitis. J. Dairy Sci. 96:4983-4992.

Venjakob, P. L., S. Borchardt, G. Thiele, and W. Heuwieser. 2016 Evaluation of ear skin temperature as a cow-side test to predict postpartum calcium status in dairy cows. J. Dairy Sci. 99:65426549 .

Wenz, J. R., G. M. Barrington, F. B. Garry, R. P. Dinsmore, and R. J. Callan. 2001. Use of systemic disease signs to assess disease severity in dairy cows with acute coliform mastitis. J. Am. Vet. Med. Assoc. 218:567-572.

Zaninelli, M., V. Redaelli, F. Luzi, V. Bronzo, M. Mitchell, V. Dell'Orto, V. Bontempo, D. Cattaneo, and G. Savoini. 2018. First evaluation of infrared thermography as a tool for the monitoring of udder health status in farms of dairy cows. Sensors (Basel) 18:862. 